\section{MARINE ENGINEERING}

Die Schiffsmaschine: ihre Construction, Wirkungsweise und Bedienung. Bearbeitet von Carl Busley, \&c. (Kiel, 1883.)

THIS is designed to be a manual and book of reference 1 on marine engineering, for the use of cngineers, naval officers, students, and others interested in steam. ships. The author is a marine engineer in the Imperial German service, and a professor at the Naval Academy of Kiel. He has laid down a most comprehensive scheme for the work, and the first and second divisions already published contain good evidence that the book when completed will become the standard German work on the subject.

Marine engineering has made great strides in recent years, and is now much more largely regulated by scientific methods than it was formerly. The earlier textbooks have become obsolete to a great extent, and a demand has arisen for new works in which modern prin. ciples and practice should be represented. In response to this demand two or three excellent books have recently been published in this country; and Mr. Busley has determined to do a similar service for Germany. It is but right to say that his book will bear very favourable comparison with any book of the class yet published, and it surpasses all of them in the fulness and beauty of the illustrations, which are contained in separate atlases and printed in colours, on a scale which makes many of them virtually working drawings.

Theoretical investigation and practical information on the details of the construction and management of marine engines and boilers both find a place in this book. Its arrangement is admirable. First, there is a clear and succinct description of the principles of the mechanical theory of heat, followed by a discussion of the properties of steam. Next comes a chapter on combustion, including a summary of the conditions essential to good boilers, and a statement of the steam-producing powers of various kinds of coal. If there is not much novelty in this section of the book, it is full of useful information. In the fourth chapter there is a long discussion of the various matters affecting the performance and economy of marine engines; details as to coal-consumption in various types of engines, with methods for estimating the expenditure of steam and coal in ships of new design; definitions of horsepower, nominal, effective, and indicated; together with remarks on various systems of condensing steam, \&c.

Following these introductory chapters, three others are devoted to marine boilers, their construction and management, including the best means of preserving them. These chapters are chiefly of a practical character, and will repay careful study, as they contain a most valuable summary of information and good rules for guidance. The eighth chapter is also of a practical nature, containing detailed examples of the auxiliary engines used for a vast variety of purposes in steamships. Amongst these may be mentioned the turret-turning and air-compressing engines of modern war-ships; steam-steering engines of various types; engines employed for heaving-up anchors and cables; others used in the production of the electric lights now generally carried by war-ships or large passenger steamers ; pumping engines; steam-winches; ventilating machinery; appliances for condensing fresh water, \&c. All of these and many others are described and illustrated in a manner which makes this portion of the book most valuable for reference. No similar summary of information on these important, if subordinate, portions in the equipment of a steamship has been previously published; and Mr. Busley deserves great credit for his perception of the necessity for and value of the information herein collected.

The ninth, tenth, and eleventh chapters relate to the construction and theory of the various types of marine engines which are or have been in use. Full descriptions and drawings are given of different systems-including some which are, as yet, only in the experimental stage; screw-steamers, paddle-steamers, and vessels driven by water-jets all come under review; and very valuable tables are given of the dimensions and particulars of the machinery in a large number of German, English, and French ships. Mr. Busley throughout displays a cosmopolitan spirit in his massing of facts, and this makes his book all the more valuable. The theoretical investigations include rules for estimating the engine-power required to attain the assigned speed of a ship; examples of the analysis of indicator diagrams for simple and compound engines; graphic processes for dealing with the slide-valves; and detailed investigations or descriptions of slide-valve gear, steering gear, \&c.

This completes the contents of the first half of this book; the other half has yet to be published, we believe. If it maintains the high character of the part already given to the world, the book will be certain to achieve success. It has been produced in excellent style, both as regards letterpress and illustrations. Its chief value consists no doubt in the large amount of information respecting modern practice which has been brought together; but the treatment of the scientific branches of the subject will assist to secure its favourable reception by the classes of readers for whom it is especially designed.

\section{OUR BOOK SHELF}

Gride to the Calcutta Zoological Gardens. By John Anderson, M.D., F.R.S., Honorary Secretary and Treasurer. (Printed by order of the Honorary Committee of Management, Calcutta, I883.)

ALTHOUGH the meritorious idea of starting a zoological garden at Calcutta was put forward by the well-known naturalist MacClelland as long ago as 1842 , and several attempts were subsequently made to carry out the plan, it was not until I875, chiefly, we believe, owing to the exertions of the late Mr. Schwendler, the telegraph engineer, that an appropriate site was obtained, and the present gardens were founded. After eight years of development the Zoological Gardens of Calcutta, under the energetic rule of the present Honorary Director, have attained a degree of arrangement sufficiently stable to allow of a "Guide" being prepared. Dr. Anderson's able pen has accordingly been employed in describing the institution which he has so well organised.

For a "Guide" Dr. Anderson's volume is perhaps rather bulky, and the type employed unnecessarily large. It is also, we may add, in our opinion a little too learned for a popular handbook. But the information contained in it, compiled as it is by one of the leading zoologists of India, may be generally depended upon, and so much can scarcely be said for some similar publications. At 